\title{
Key uncertainty sources analysis of water quality model using the first order error method
}

\author{
${ }^{1}$ X. Zhao; ${ }^{1 * Z . ~ Y . ~ S h e n ; ~}{ }^{2}$ M. Xiong; ${ }^{3} J . Q$ Qi \\ ${ }^{1}$ State Key Laboratory of Water Environment Simulation, School of Environment, Beijing Normal \\ University, Beijing 100875, P. R. China \\ ${ }^{2}$ Bureau of Hydrology, Changjiang Water Resources Commission, Wuhan, Hubei Province 430010, \\ P. R. China \\ ${ }^{3}$ Beijing Municipal Research Institute of Environmental Protection, Beijing 100037, P. R. China \\ Received 7 July 2010; $\quad$ revised 5 October 2010; accepted 24 November 2010; $\quad$ available online 1 December 2010
}

\begin{abstract}
In this study, key uncertainty sources analysis was undertaken for a dynamic water model using a First order error analysis method. First, a dynamic water quality model for the Three Gorges Reservoir Regions was established using data after impoundment by the environmental fluid dynamics code model package. Model calibration and verification were then conducted using measured data collected during 2004 and 2006. Four statistical indices were employed to assess the modeling efficiency. The results indicated that the model simulated the variables well, with most relative error being less than $25 \%$. Next, input and parameter uncertainty analysis were conducted for ammonia nitrogen, nitrate nitrogen, total nitrogen, and dissolved oxygen at 3 grid cells located in the upper, middle and downstream portions of the research area. For the nitrogen related variables, input from Zhutuo Station, the Jialingjiang River, and the Wujiang River were the main sources of uncertainty. Point and nonpoint sources also accounted for a large ratio of uncertainty. Moreover, nitrification contributed some uncertainty to the estimated ammonia nitrogen and nitrate nitrogen. However, reaeration was found to be a key source of uncertainty for dissolved oxygen, especially at the middle and downstream reaches. The analysis conducted in this study gives a quantitative assessment for uncertainty sources of each variable, and provides guidance for further pollutant loading reduction in the Three Gorge Reservoir Region.
\end{abstract}

Key words: Dissolved oxygen; Environmental Fluid Dynamics Code; Model; Nitrogen; Water quality

\section{INTRODUCTION}

Recently, water quality models have been widely employed worldwide for water environment assessment and prediction in various water bodies including lakes, reservoirs, oceans, rivers and estuaries, a case in point is oil spill model in estuaries water (Nagheeby and Kolahdoozan, 2010; Kuok et al., 2010). Indeed, in the United States, water quality models have become essential tools for estimating the distribution of the total maximum daily load (TMDL) and developing best management practices (BMPs), (EPA, 2009; Turner et al., 2009; Iginosa and Okoh, 2009; Chen et al., 2010). The transport and fate of water quality constituents in the water column are simulated using modeling modules such as river and stream water Quality Model

凶*Corresponding Author Email: zyshen@bnu.edu.cn Tel.: +8610 5880 0398; Fax: +861058800398
(QUAL2K), (Chapra et al., 2007), water quality analysis simulation program (WASP) (Wool et al., 2001), environmental fluid dynamics code (EFDC) (Tetra Tech, 2007)and MIKE11 (DHI, 2003), which describe the problems related to chemical and biological processes through deterministic partial differential equations (Igwe et al., 2008; Shah et al., 2009). These models are deterministic because they provide a single response for each set of parameters, initial and boundary conditions (Bobba et al., 1996). However, there is always uncertainty associated with models. In general, uncertainty comes from four aspects when modeling water quality (Radwan et al., 2004): (I) structural uncertainties; specifically, basic processes mathematically characterizing changes in variables in the water column may not be always identical in 
different models, and some processes may be ignored or combined with others. For example, in the EFDC model (Tetra Tech, 2007), organic nitrogen is divided into refractory particulate organic nitrogen, liable particulate organic nitrogen and dissolved organic nitrogen; however, in the WASP (Wool et al., 2001) model, it is a single variable; (II) parameter uncertainty; specifically, a set of parameters suitable for one model may be lower quality than in other models as a result of different climatic, topographic, and hydrodynamic conditions; (III) input uncertainty; specifically, future loadings based on projections may be over or under estimated; and (IV) measurement uncertainty, measurement results are closely related to researcher's experiences and precision of instruments.

Many methods have been proposed to assess the uncertainty associated with various resources quantitatively, including the following: first order error analysis (FOEA), which is a procedure based on first order terms in the Taylor series expansion of the dependent variable around its mean value with respect to one or more independent variables (Bobba et al., 1996; Abrishamchi et al., 2005); Monte Carlo (Tomassini and Reichert, 2007), which uses a large number of simulations with the values for stochastic inputs or uncertain variables being selected at random from their assumed parent probability distributions to establish an expected range of model uncertainty; Markov Chain Monte Carlo, a modified MC method that includes the Markov chain analysis (Tomassini and Reichert, 2007); generalized likelihood uncertainty estimation, which works with multiple sets of factors, typically via Monte Carlo sampling, and applies likelihood measures to estimate the predictive uncertainty of the model (Ratto and Saltelli, 2001; Soner Kara and Onut, 2010); point estimation method (PEM), in which the probability distribution function (PDF) of each random input variable is represented by a number $\mathrm{N}_{\mathrm{p}}$ of discrete points located according to the first, second and third moments of the PDF, and the joint PDF of $\mathrm{N}_{\mathrm{par}}$ parameters is represented by the array of projected points (Franceschini and Tsai, 2010).

For large, complex dynamic models with disperse parameter distributions, FOEA may be computationally feasible, and do not specify parameter distributions, which is an important issue to consider in methods such as MC. Unfortunately, the effect of different choices of distributions is difficult to assess (USEPA, 1999). Furthermore, FOEA provides a very clear approach to uncertainty analysis by decomposing the variance of each output into the sum of contributions from each input. Therefore it allows explicit consideration of the combined effects of parameter sensitivity and parameter uncertainty in the determination of the key parameters affecting modelprediction uncertainty and is easy to update the risk estimation when new information becomes available (Zhang and Yu, 2004). So, FOEA is a more suitable tool for uncertainty analysis in the Three Gorges Reservoir Region (TGRR). Modeling research has been undertaken for more than 20 years in the TGRR. In 1991, the Report on the Impact of the Three Gorges Project (TGP) on Ecology and the Environment was completed by the Changjiang Water Resources Protection Institute in cooperation with the Chinese Academy of Sciences and other institutes. However, due to technical limitations, qualitative evaluation of the effects of water impoundment on water quality was only preliminarily conducted in this study, and only a few empirical formulas and simple mathematical models were used (Yu, 2008). From 1989 to 2001, the Chongqing Environmental Science Institute in cooperation with research institutes from the United Kingdom and Denmark launched a series of hydrodynamic and water quality simulations in the Chongqing section of the TGRR using 2-D and quasi 2-D vertically mixed models. In their study, the chemical oxygen demand (COD), $\mathrm{NH}_{4}-\mathrm{N}$, Biochemical oxygen demand $\left(\mathrm{BOD}_{5}\right)$ and other water quality parameters were simulated; however, changes in the water environment throughout the entire reservoir were not considered. ${ }^{1}$ In 1996 , a systemic research program known as the Water Pollution Control in the Three Gorges Reservoir Area Program was launched by the Three Gorges Project Construction Commission of the State Council and several research organizations (Huang et al., 2006). Three topics were included in this program: (1) identification of current pollution loads and forecast of the pollution trend; (2) analysis of changes in water quality caused by water impoundment; and (3) assignment of the aquatic environmental capacity of pollutants to meet specified water quality standards. To predict the water environmental quality under different impoundment conditions, a 1-D hydrodynamic and water quality model was developed by the China Institute of Water Resources and Hydropower Research for the entire reservoir area, from the dam to about $660 \mathrm{~km}$ upstream( $\mathrm{Li}$ et al., 2002). However, due to restrictions in the basic 
data, the model does not take into account the impact of sediments and some biochemical processes had to be simplified. For example, phosphorus was treated as a conservative substance in the model. In this study, a large scale dynamic water quality model was provided for the whole TGRR, and the modeling task has been lasted about 10 months from March, 2008. When compared to previously conducted modeling practices, data from 2004 and 2006 were used to calibrate and validate the model, and these data can further reflect changes in water quality after impoundment. Additionally, the latest measured point and nonpoint sources data were used as important external sources of variables and the model kinetic processes were more complex than forgone models. Next, detailed input and parameter uncertainty analysis was conducted using the FOEA method because a great deal of uncertainty analysis in water quality modeling is grouped in static and simple kinetic processes such as QUAL2E, while they are relatively rare for dynamic and complex model systems.

\section{MATERIALS AND METHODS}

Study Area

The TGRR ranges from Chongqing City to Yichang City, Hubei Province $\left(106^{\circ} 16^{\prime} \sim 111^{\circ} 28^{\prime} \mathrm{E}\right.$, $28^{\circ} 56^{\prime} \sim 31^{\circ} 44^{\prime} \mathrm{N}$ ) (Fig. 1). This region refers to the area affected by the water impoundment of the TGP and covers an area of $54,000 \mathrm{~km}^{2}$ (Zhang et al., 2009). Most of this area is mountainous, with the western portion having an elevation ranging from 1000 to $2500 \mathrm{~m}$ and the eastern portion having an elevation of about 500 $900 \mathrm{~m}$. The study area is subject to the tropical monsoon climate of Northern Asia and has an annual mean temperature, precipitation, evaporation rate and wind speed of $18{ }^{\circ} \mathrm{C}, 1170 \mathrm{~mm}, 1300 \mathrm{~mm}$ and $1.4 \mathrm{~m} / \mathrm{s}$, respectively. In the TGRR, water is quite plentiful, with an average flow of 40.56 billion $\mathrm{m} 3$ per year, of which underground runoff accounts for about $21 \%$. However, the temporal and spatial distribution of water in the region is very uneven and the Northwest is short of water during the spring and winter. There are more than 200 tributaries with a drainage area that is greater than $100 \mathrm{~km}^{2}$ in the TGRR, including the Jialing, Wujiang and Daninghe rivers (Deng, 2007).

\section{Model Description}

The EFDC model package, which was originally developed by John Hamrick at the Virginia Institute of Marine Science (VIMS), is a general purpose threedimensional modeling package for flow, pollutant transport and biogeochemical processes in surface water systems including rivers, lakes, estuaries, reservoirs, wetlands and coastal regions(Tetra Tech,

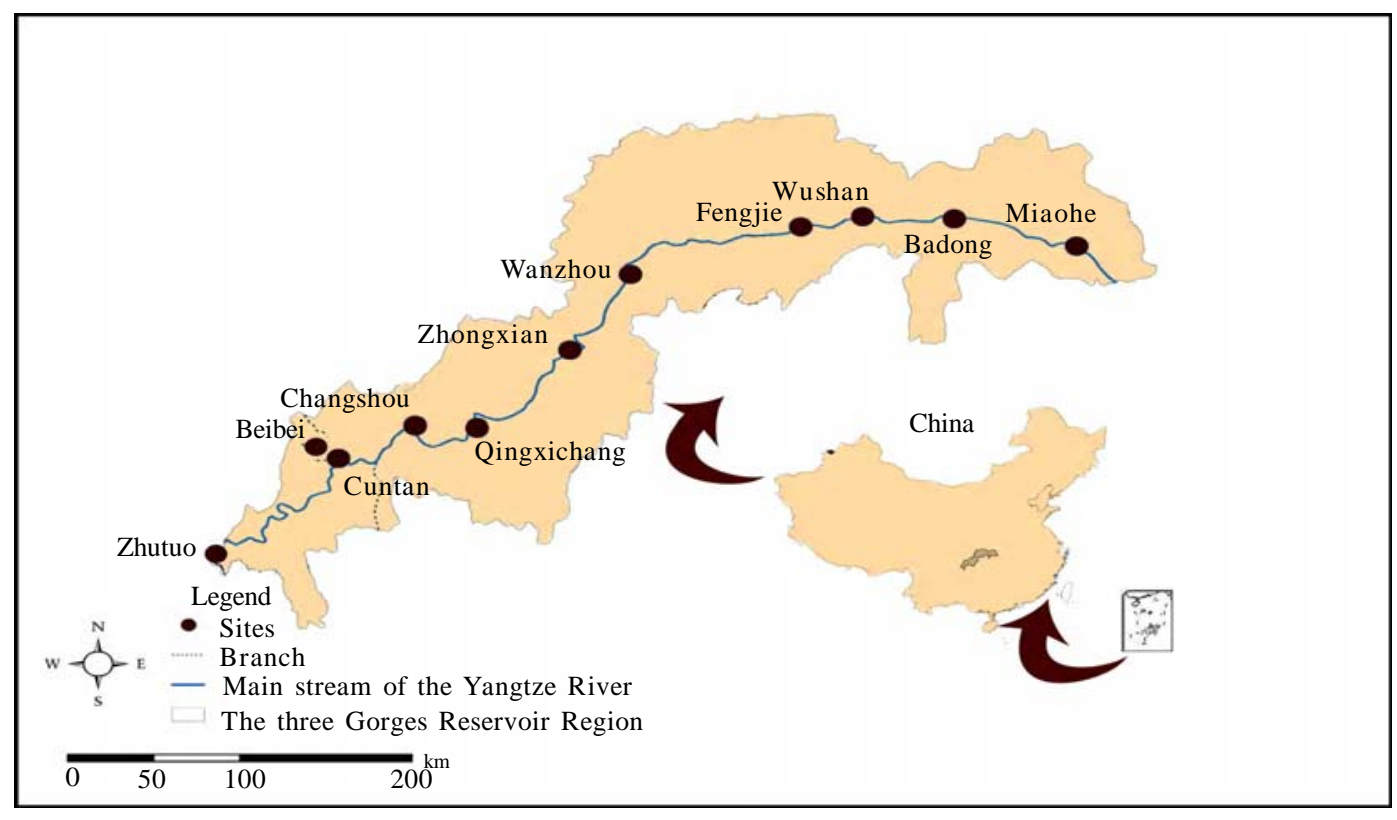

Fig. 1: Location of monitoring stations in the TGRR 
2007). The structure of the EFDC model includes four major modules: (1) a hydrodynamic sub-model, (2) a water quality sub-model, (3) a sediment transport submodel and (4) a toxics sub-model. The water column water quality model simulates the spatial and temporal distributions of 21 state variables in the water column. For each state variable, a mass conservation equation (Eq. 1) is established:

$$
\begin{aligned}
& \frac{\partial C}{\partial t}+\frac{\partial(C u)}{\partial x}+\frac{\partial(C v)}{\partial y}+\frac{\partial(C w)}{\partial z}= \\
& \frac{\partial}{\partial x}\left(K_{x} \frac{\partial C}{\partial x}\right)+\frac{\partial}{\partial y}\left(K_{y} \frac{\partial C}{\partial y}\right)+\frac{\partial}{\partial z}\left(K_{z} \frac{\partial C}{\partial z}\right)+S_{c}
\end{aligned}
$$

where $C$ is the concentration of a water quality state variable; $u, v$ and $w$ are the water velocity components in the $\mathrm{x}, \mathrm{y}$ and $\mathrm{z}$ directions, respectively, and $K_{\mathrm{x}}, K_{\mathrm{y}}$ and $K_{\mathrm{z}}$ are the turbulent diffusivities in the $\mathrm{x}, \mathrm{y}$ and $\mathrm{z}$ directions, respectively. In addition, $S_{c}$ represents the internal and external sources and sinks of the water quality state variable, which are those generated/ consumed by kinetic processes. The kinetic formulations in the model are primarily from CE-QUALICM (Cerco and Cole, 1994).

\section{Data Preparation}

In this study, the basic data sets required to develop the models included bathymetry, hydrology, meteorological data and water quality data. A topographic map with a resolution of 1:25,000 was used to delineate the channel characteristics, and bathymetry data collected from along the river was obtained from the available literature (Huang et al., 2006). Hydrology and water quality data, including the $\mathrm{DO}, \mathrm{BOD}_{5}, \mathrm{NH}_{4}-\mathrm{N}, \mathrm{NO}_{3}-\mathrm{N}$ and $\mathrm{TN}$, collected from 2003 to 2007 at 12 monitoring stations in the research area were obtained from the Bureau of Hydrology, Changjiang Water Resources Commission. Meteorological data from 2003 to 2007 were downloaded from the website maintained by the Chingqing Meteorological Bureau. Industrial and municipal point pollution sources for each county and district in 2002 in the TGRR were obtained from the China Environmental Science Research Institute (CRAES), and data from 2004 to 2007 were obtained from the Three Gorges Bulletins (MEP, 2010). Nonpoint source nutrient emission data were obtained from Zhen et al. (2009).

\section{Model Configuration, Calibration and Validation}

SEAGRID (Denham, 2006) was applied to create orthogonal curvilinear grids, while the GEFDC software was used to create dxdy.inp and lxly.inp files(Tetra Tech, 2007). For the initial condition, the water surface elevation (WSE) and water quality variables for each active cell were interpolated based on monitoring data collected along the Changjiang River. For water variables, various species of nitrogen and carbon were estimated according to Ji (2008) and field data. Zhutuo, Beibei and Wulong Stations were treated as the inflow boundary, while the open boundary was the downstream area of the Three Gorges Dam. Meteorological conditions were used as the driving function for the model. Default parameters were initially used to run the model and were later adjusted during calibration with the data from 2004. Model validation was conducted using the data from 2006. Simulation results were evaluated using 4 predefined statistics parameters: Average error (AE), Relative error (RE); Average absolute error (AAE) and Root mean square error (RMSE).

\section{FOEA method}

In FOEA, a function $Y=f(X)$, was approximated by a first order Taylor series expansion around the expected $X$ :

$$
Y=Y\left(X_{e}\right)+\sum_{i=1}^{p}\left(X_{i}-X_{i e}\right)\left(\partial Y / \partial X_{i}\right)_{X_{e}}
$$

where $Y=$ the concentration of the constituent simulated in the selected water quality model; $X_{e}=$ the vector of uncertain basic variables representing the expansion point; $p=$ the number of basic variables $X$. The expansion point is commonly the mean value (or some other convenient central value) of the basic variables. Thus, the expected value and variance of the performance function can be expressed as follows:

$$
\begin{aligned}
& E(Y) \approx Y\left(X_{m}\right) \\
& \operatorname{Var}(Y)=\sigma_{Y}^{2} \approx \sum_{i=l i=I}^{p} \sum_{i=1}^{p}\left(\partial Y / \partial X_{i}\right)_{X_{m}} \\
& \left(\partial Y / \partial X_{j}\right)_{X_{m}} E\left[\left(X_{i}-X_{m i}\right)\left(X_{i}-X_{j i}\right)\right]
\end{aligned}
$$

where $\sigma_{Y}=$ the standard deviation of $Y$; and $X_{m}=$ the vector of mean values of the basic variables. If the basic variables are statistically independent, the variance of $Y$ becomes

$\operatorname{Var}(Y)=\sigma_{r}^{2}=\sum_{i=1}^{p}\left[\left(\partial Y / \partial X_{i}\right) \sigma_{i}\right]^{2}$ 
When $\Delta X \rightarrow 0$, Equation (4) becomes

$\operatorname{Var}(Y)=\sum_{i=1}^{p} \operatorname{Var}\left(X_{i}\right)\left(\frac{\Delta Y}{\Delta X_{i}}\right)^{2}$

Then

$$
\begin{aligned}
& \frac{\operatorname{Var}(Y)}{Y^{2}}=\sum_{i=1}^{p} \operatorname{Var}\left(X_{i}\right) \frac{\left(\Delta Y / \Delta X_{i}\right)^{2}}{Y^{2}} \\
& \frac{\operatorname{Var}(Y)}{Y^{2}}=\sum_{i=1}^{p} \frac{\operatorname{Var}\left(X_{i}\right)}{X_{i}^{2}} \frac{\left(\Delta Y / \Delta X_{i}\right)^{2}}{Y^{2} / X_{i}^{2}} \\
& \frac{[\sigma(\mathrm{Y})]^{2}}{Y^{2}}=\sum_{i=1}^{p} \frac{\left[\sigma\left(X_{i}\right]^{2}\right.}{X_{i}^{2}} \frac{(\Delta Y / Y)^{2}}{\left(\Delta X_{i} / X_{i}\right)^{2}}
\end{aligned}
$$

$[\mathrm{SD}(\mathrm{Y})]^{2}=\sum_{i=1}^{p}\left[C V\left(X_{i}\right)\right]^{2}\left[\frac{(\Delta Y / Y)}{\left(\Delta X_{i} / X_{i}\right.}\right]^{2}$

$[\mathrm{SD}(\mathrm{Y})]^{2}=\sum_{i=1}^{p}\left[C V\left(X_{i}\right)\right]^{2}\left(S_{i}\right)^{2}$

where $\operatorname{Var}\left(X_{i}\right)=$ the variance of basic variables; $S D(\mathrm{Y})=$ the standard deviation of the output; $C V(\mathrm{X})=$ the coefficient of variation; $S_{i}=$ the normalized sensitivity coefficient.

\section{RESULTS AND DISCUSSION}

Model Calibration and Verification

Based on the availability of the measured data, the data obtained from the Cuntan, Qingxichang and Wanzhou monitoring stations (Fig. 1) were selected for parameter calibration and verification. The modeled periods were 2004 and 2006 . The time step was 60s, and it took about $1 \mathrm{~h}$ to complete model implementation. The simulation results were compared with measured data as follows: a time series comparison at each station, a longitudinal profile comparison for the entire reservoir region, and a statistical table (Table 1). For the purpose of simplicity, this paper only provides the time series comparison for Wanzhou Station.

Figs. 2a-f provide a comparison of results obtained for Wanzhou station during the calibration period. Fig. 2a shows that the simulated and measured WSE matched very well before and after the high flow period, and that the simulation results were slightly larger than the corresponding measured values during the high flow period. This may have been caused by abundant inflows from other ignored tributaries in the reservoir region such as the Yulin River, the Zhuxi River and the Xiaojiang River. These findings indicate that the extreme peak value of the measured data cannot always be reproduced in the modeling process. With respect to temperature (Fig. 2b), the computations are in good agreement with the observed data. The DO concentration is important for supporting the aquatic ecosystem, and prolonged exposures to less than $60 \%$ oxygen saturation may result in altered behavior, growth reduction, adverse reproductive effects and mortality. Fish will begin to feel stress when the DO drops to about $4 \mathrm{mg} / \mathrm{L}$ and will swim away from areas in which the DO is below $3 \mathrm{mg} / \mathrm{L}$. Fish that are unable to swim

\begin{tabular}{|c|c|c|c|c|c|c|c|c|c|}
\hline \multirow{2}{*}{ Station ID } & \multirow{2}{*}{ Variable } & \multicolumn{4}{|c|}{2004} & \multicolumn{4}{|c|}{2006} \\
\hline & & $\mathrm{AE}$ & $\mathrm{RE}$ & AAE & RMS & $\mathrm{AE}$ & $\mathrm{RE}$ & AAE & RMS \\
\hline Qingxichang & WSE(m) & 0.76 & 0.56 & 0.79 & 0.94 & 0.91 & 0.67 & 0.96 & 8.08 \\
\hline Cuntan & Temperature $\left({ }^{\circ} \mathrm{C}\right)$ & -0.27 & 4.88 & 1.05 & 1.41 & -0.28 & 4.96 & 1.05 & 1.36 \\
\hline Qingxichang & Temperature $\left({ }^{\circ} \mathrm{C}\right)$ & -0.83 & 8.19 & 1.75 & 2.14 & -0.74 & 6.01 & 1.29 & 1.61 \\
\hline Wanzhou & Temperature $\left({ }^{\circ} \mathrm{C}\right)$ & -0.4 & 5.57 & 1.21 & 1.58 & -0.3 & 5.67 & 1.23 & 1.59 \\
\hline Qingxichang & DO $\left(\mathrm{g} / \mathrm{m}^{3}\right)$ & -0.16 & 7.01 & 0.63 & 0.77 & 1.82 & 24.57 & 1.82 & 1.93 \\
\hline Wanzhou & $\mathrm{DO}\left(\mathrm{g} / \mathrm{m}^{3}\right)$ & -0.17 & 5.84 & 0.47 & 0.59 & 0.53 & 8.65 & 0.68 & 0.78 \\
\hline Cuntan & $\mathrm{NH}_{4}-\mathrm{N}\left(\mathrm{g} / \mathrm{m}^{3}\right)$ & 0.05 & 44.58 & 0.07 & 0.08 & -0.02 & 24.48 & 0.05 & 0.07 \\
\hline Qingxichang & $\mathrm{NH}_{4}-\mathrm{N}\left(\mathrm{g} / \mathrm{m}^{3}\right)$ & 0.01 & 42.56 & 0.07 & 0.09 & 0.01 & 17.56 & 0.03 & 0.04 \\
\hline Wanzhou & $\left.\mathrm{NH}_{4}-\mathrm{N} \mathrm{g} / \mathrm{m}^{3}\right)$ & -0.04 & 35.93 & 0.07 & 0.1 & -0.03 & 24.64 & 0.06 & 0.07 \\
\hline Cuntan & $\mathrm{NO}_{3}-\mathrm{N}\left(\mathrm{g} / \mathrm{m}^{3}\right)$ & -0.09 & 7.85 & 0.11 & 0.15 & 0.01 & 9.67 & 0.12 & 0.16 \\
\hline Wanzhou & $\mathrm{TN}\left(\mathrm{g} / \mathrm{m}^{3}\right)$ & 0.17 & 14.27 & 0.25 & 0.31 & 0.91 & 0.67 & 0.96 & 8.08 \\
\hline
\end{tabular}
away from such areas and shell fish will begin to die

Table 1: Simulated Results analysis in Cuntan, Qingxichang and Wanzhou Stations 
X. Zhao et al.
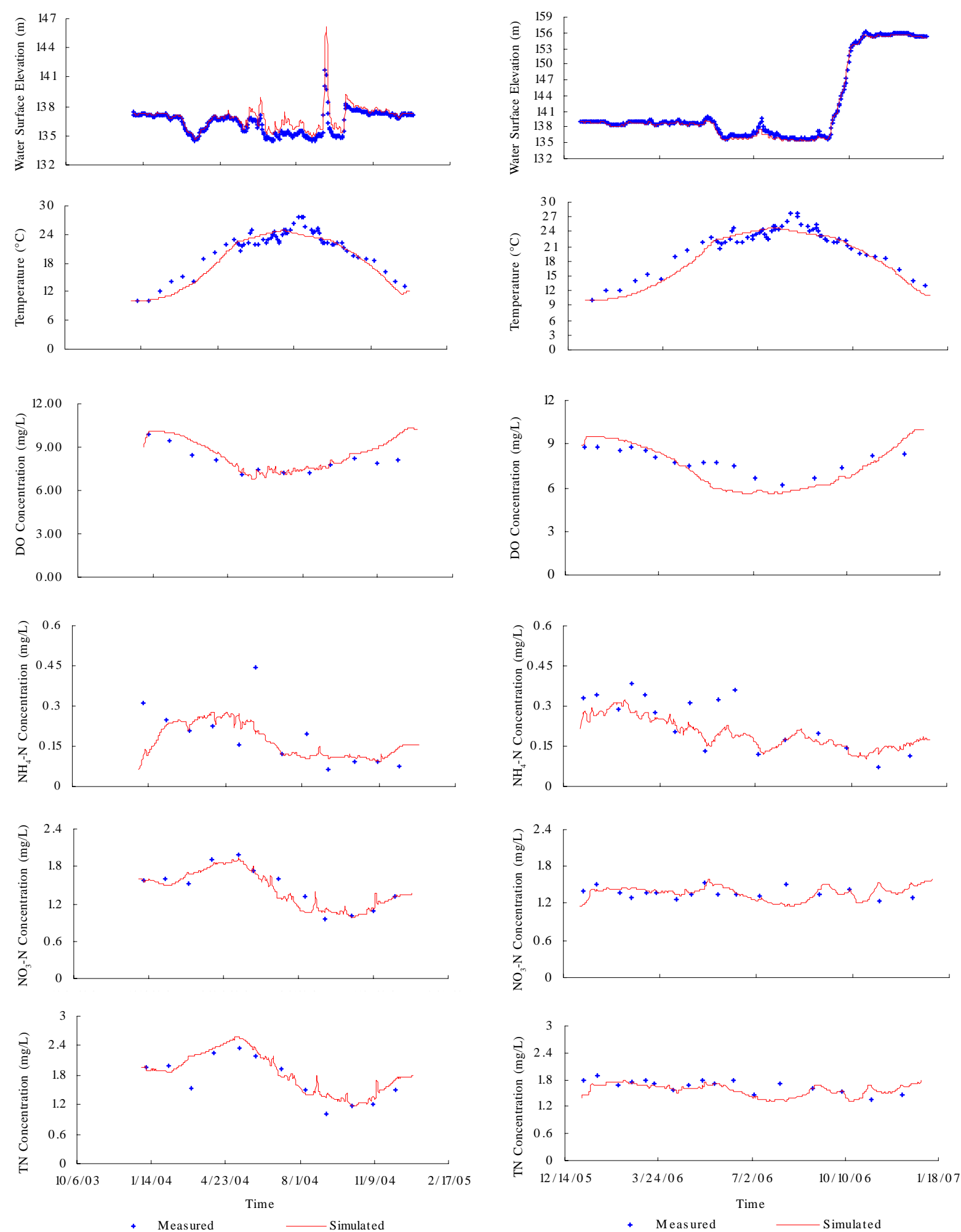

Fig. 2: Comparison of simulated and measured results in Wanzhou station 
when the DO is below this level (Karim et al., 2002). The comparison plot in Fig. 2c indicates that the measured change in DO concentration was duplicated by the model. The change in the temporal $\mathrm{NH}_{4}-\mathrm{N}$ concentration was also represented by the model (Fig. 2d), but larger discrepancies existed at some times, possibly due to the enormous variation in field measured data, which ranged from $<0.1 \mathrm{mg} / \mathrm{l}$ during the low flow period to $0.45 \mathrm{mg} / \mathrm{l}$ in the high flow period. The $\mathrm{NO}_{3}-\mathrm{N}$ (Fig. 2e) and $\mathrm{TN}$ (Fig. 2f) showed the same trend, which was likely because $\mathrm{NO}_{3}-\mathrm{N}$ accounts for the highest ratio of the TN in the TGRR (Huang et al., 2006). The simulated $\mathrm{NO}_{3}-\mathrm{N}$ and $\mathrm{TN}$ were close to the field data, which was probably due to the fact that the $\mathrm{NO}_{3}-\mathrm{N}$ concentration was less affected by external loads such as non-point sources during the high flow period.

Figs. 2a'-f' provide a comparison of the results obtained in Wanhzou during the verification period. The WSE (Fig. 2a') and temperature (Fig. 2b') were modeled well by the model. Overall, the profile of the DO concentration (Fig. 2c') matched the simulated values well, despite some divergences near May, 2006. Some of the measured $\mathrm{NH}_{4}-\mathrm{N}$ concentrations were higher than the simulated values during the first half of 2006 (Fig. 2d'), and the same condition appeared during the TN simulation (Fig. 2f'). There was also a high fit between the measured and simulated $\mathrm{NO}_{3}-\mathrm{N}$ concentration during 2006 (Fig. 2e'). These results were similar to those obtained during the calibration process. Fig. 3 provides a longitudinal profile comparison along the Changjiang River for the calibration and verification period using field data from nine stations. The dates were 2004-2-10, 2004-5-10, 2004-8-10, 2006-2-10, 2006-5-10, and 2006-8-10. Figs 3a and a' indicate that the simulated WSE along the river was satisfactory for the three flow periods. The simulated DO concentrations matched the measured DO data in the upper section for each flow period (Figs. 3b and b'), but were lower than the measured DO for the downstream stations near the Three Gorges Dam. During the field measurement of DO, only the surface DO concentration was measured; however, in the model, the simulated DO was the averaged value along the water depth (Tetra Tech, 2007). For $\mathrm{NH}_{4}-\mathrm{N}$ (Figs. 3c and c'), the simulation results in the average flow period were better than in the other two periods. There was also a sharp increase in $\mathrm{NH}_{4}-\mathrm{N}$ from the distance from $140 \mathrm{~km}$ to $160 \mathrm{~km}$ due to industrial and domestic load emissions in Chongqing City. A large decrease was observed at the location at which the Jialingjiang River joins the impoundment area, and the $\mathrm{NH}_{4}-\mathrm{N}$ level continued to decay until the Changshou District (214 km from the Zhutuo station), where an increase in $\mathrm{NH}_{4}-\mathrm{N}$ concentration appeared. However, after the merge with the Wujiang River (258 $\mathrm{km}$ ), the NH4-N decreased and remained low until the Wanzhou District (458 km). Generally, the $\mathrm{NO}_{3}-\mathrm{N}$ (Fig.3d and Fig.3d') and TN (Figs. 3e and e') have the same simulation efficacy, although an increase in TN occurred at Chongqing City due to a large discharge of $\mathrm{NH}_{4}-\mathrm{N}$ in the region (MEP, 2010). Table 1 summarizes the error analyses of six modeled and observed variables at three stations during the calibration and verification periods, respectively. The results in Table 1 show that the modeling errors were low. Taking RE as an example, during 2004, the REs varied from $0.29 \%$ for WSE at the Cuntan station to $44.58 \%$ for $\mathrm{NH}_{4}-\mathrm{N}$ at the same station. In addition, the REs were less than $15 \%$ except for those of $\mathrm{NH}_{4}^{-}$ $\mathrm{N}$. Similarly, the REs of $\mathrm{NH}_{4}-\mathrm{N}$ were also higher in 2006, with the highest value of $24.64 \%$ being observed at the Wanzhou station. This may have been caused by the large range of field data from less than $0.1 \mathrm{mg} /$ $\mathrm{l}$ to greater than $0.5 \mathrm{mg} / \mathrm{L}$, and the complexity of sources and sinks (MEP, 2010).

\section{Uncertainty analysis}

Uncertainty analysis was conducted using the FOEA method, and three gird cells, grid 200, grid 450 , and grid 700 , were selected to represent the upper, middle, and lower reaches. The base model with calibrated parameters was implemented for the entire modeling period (1 y) and changes were conducted from upstream input, the Jianglingjiang River input, the Wujiang River input, point and nonpoint source input, wet deposition and related parameters for each variable with a disturbance of $5 \%$. The annual mean output of variables from the three grid cells was compared with those of the base model to calculate the normalized sensitivity coefficient $\left(S_{i}\right)$, while the $C V$ values for variables and parameters were determined according to studies conducted by Brown and Barnwell (1987) and Zhang and Yu (2004). Table 2 lists detailed model variables and parameters, units, descriptions, and $C V$ values for uncertainty analysis using the TGRR model. 

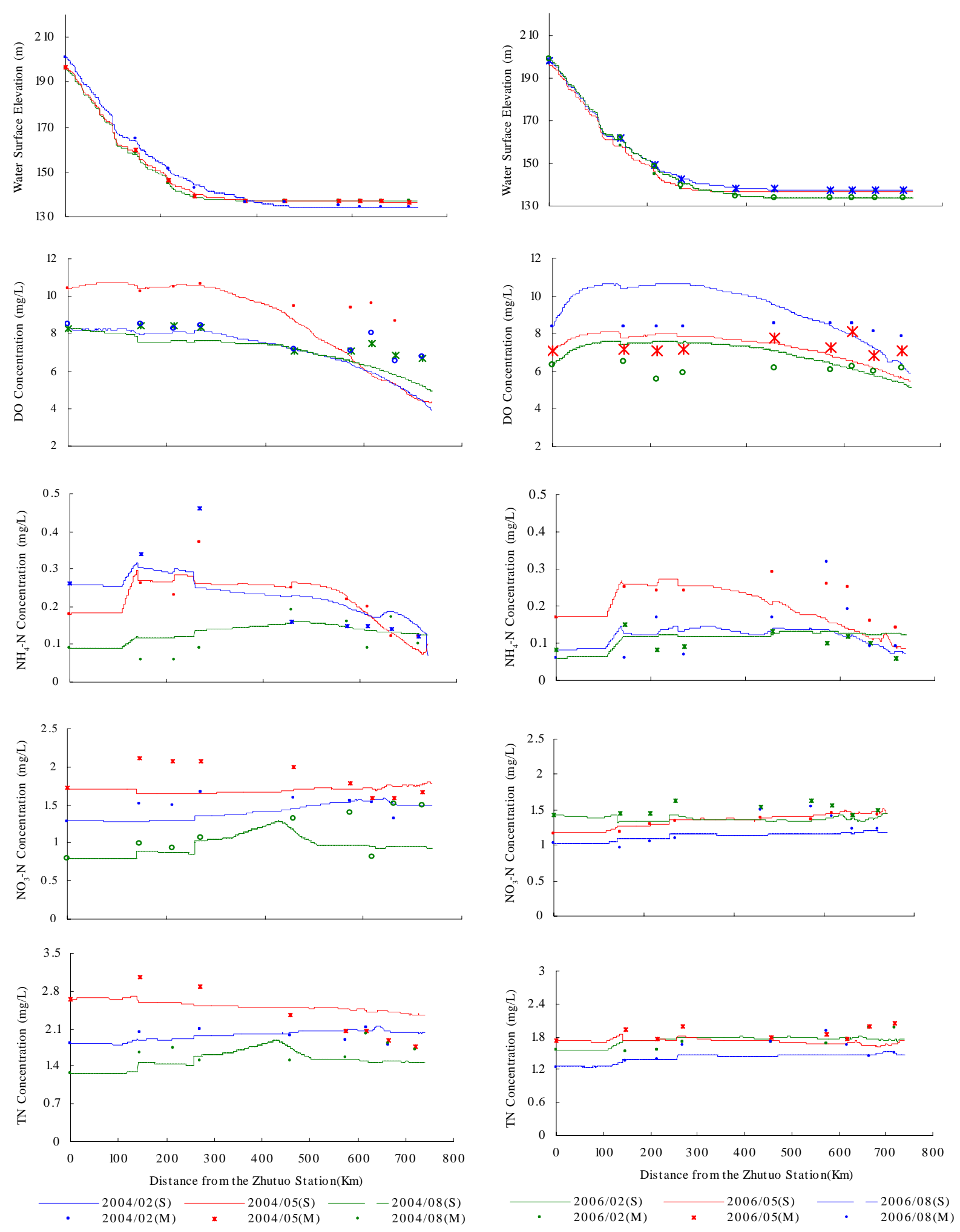

Fig. 3: Longitudinal Profile Comparison along the Changjiang river 
Table 2: Description of variables and $C V$ for uncertainty analysis of the TGRR model

\begin{tabular}{|c|c|c|c|}
\hline Variable/Parameters & Unit & Description & $C V(\%)$ \\
\hline $\mathrm{Q} 1_{\mathrm{i}}$ & $\mathrm{g} / \mathrm{m}^{3}$ & Inflow ith varibles concentration form upstream & 25 \\
\hline $\mathrm{Q} 2_{\mathrm{i}}$ & $\mathrm{g} / \mathrm{m}^{3}$ & Inflow ith varibles concentration form the Jialingjiang River & 25 \\
\hline $\mathrm{Q}_{\mathrm{i}}$ & $\mathrm{g} / \mathrm{m}^{3}$ & Inflow ith varibles concentration form the Wujiang River & 25 \\
\hline ES & $\mathrm{g} / \mathrm{m}^{3}$ & External source of ith varibles (point and nonpoint sources) & 25 \\
\hline WD & $\mathrm{g} / \mathrm{m}^{3}$ & ith varibles concentration from wet deposition & 25 \\
\hline TNit & ${ }^{\circ} \mathrm{C}$ & Optimum temperature for nitrification & 5 \\
\hline $\mathrm{Nit}_{\mathrm{m}}$ & $\mathrm{gNm}^{-3} /$ day & Mmaximum nitrification rate at TNit & 10 \\
\hline $\mathrm{KHNit}_{\mathrm{DO}}$ & $\mathrm{gO}_{2} / \mathrm{m}^{3}$ & Nitrification half-saturation constant for dissolved oxygen & 10 \\
\hline $\mathrm{KHNit}_{\mathrm{N}}$ & $\mathrm{gN} / \mathrm{m}^{3}$ & Nitrification half-saturation constant for ammonium & 10 \\
\hline KNit1 & ${ }^{\circ} \mathrm{C}^{-2}$ & Effect of temperature below TNit on nitrification rate & 5 \\
\hline $\mathrm{KROR}_{\mathrm{DO}}$ & $\mathrm{g} \mathrm{O} / \mathrm{m}^{3}$ & denitrification half-saturation constant for dissolved oxygen & 10 \\
\hline KNit2 & ${ }^{\circ} \mathrm{C}^{-2}$ & Effect of temperature above TNit on nitrification rate & 5 \\
\hline $\mathrm{KHDN}_{\mathrm{N}}$ & $\mathrm{gN} / \mathrm{m}^{3}$ & Denitrification half-saturation constant for nitrate & 10 \\
\hline AANOX & - & Ratio of denitrification rate to oxic dissolved organic carbon respiration rate & 10 \\
\hline KDN & 1/Day & Minimum mineralization rate of dissolved organic nitrogen & 10 \\
\hline KTMNL & 1/Day & Effect of temperature on mineralization of dissolved organic matter & 5 \\
\hline TRMNL & 1/Day & Reference temperature for mineralization of dissolved organic matter & 5 \\
\hline TRHDR & 1/Day & Reference temperature for hydrolysis of particulate organic matter & 5 \\
\hline KRN & 1/Day & Minimum hydrolysis rate of refractory particulate organic nitrogen & 10 \\
\hline KLN & 1/Day & Minimum hydrolysis rate of labile particulate organic nitrogen & 10 \\
\hline KTHDR & 1/Day & Effect of temperature on hydrolysis of particulate organic matter & 5 \\
\hline WSRP & $\mathrm{m} /$ day & Settling velocity of refractory particulate organic matter & 10 \\
\hline WSLP & $\mathrm{m} /$ day & Settling velocity of labile particulate organic matter & 10 \\
\hline $\mathrm{KHOR}_{\mathrm{DO}}$ & $\mathrm{gO}_{2} / \mathrm{m}^{3}$ & Oxic respiration half-saturation constant for dissolved oxygen & 5 \\
\hline KDC & 1/Day & Minimum respiration rate of dissolved organic carbon & 10 \\
\hline $\mathrm{KTr}$ & - & Constant for temperature adjustment of DO reaeration rate. & 10 \\
\hline
\end{tabular}

As shown in Table 3, the inflow $\mathrm{NN}_{4}-\mathrm{N}$ from the upper boundary, Zhutuo station at the main stream, is the largest factor controlling the $\mathrm{NH}_{4}-\mathrm{N}$ concentration in the TGRR. However, the effect decreases from 75.02 $\%$ at the upstream grid to $22.62 \%$ at the downstream one. The effects from the Jialingjiang River (grid 158) and the Wujiang River (grid 285) were similar. External sources (point and nonpoint) account for a high ratio leading to the $\mathrm{NH}_{4}-\mathrm{N}$ concentration uncertainty in the reservoir region, and the PTV in grid 200, grid 450, and grid 700 were $18.60 \%$, $28.55 \%$, and $20.31 \%$, respectively. The large quantity of $\mathrm{NH}_{4}-\mathrm{N}$ discharged from industrial, domestic, and agricultural activities in the TGRR may be the principal reason for these findings(Zhen et al., 2009; MEP, 2010). Nitrification is a major process affecting the $\mathrm{NH}_{4}-\mathrm{N}$ concentration; therefore, $\mathrm{Nit}_{\mathrm{m}}$ is the largest source of uncertainty among parameters, and the effect is more significant in the downstream grid. $\mathrm{KHNit}_{\mathrm{N}}$, which is related to nitrification, is also a large source of uncertainty with a PTV of $8.36 \%$ at grid 700. Temperature is an important factor controlling nitrification (Ji, 2008); therefore, TNit contributes a high rate of PTV.
In Table 3, The total PTV from inflow $\mathrm{NO}_{3}-\mathrm{N}$ from Zhutuo station, the Jianglingjiang River, and the Wujiang River was more than $95 \%$. The Wujiang River had a more significant effect on gird 450 and grid 700 than the Jialingjiang River. The PTVs of the point and nonpoint sources showed a progressive increase from $0.31 \%$ to $2.82 \%$ along the river. Due to nitrification $\mathrm{NH}_{4}-\mathrm{N}, \mathrm{Nit}_{\mathrm{m}}, \mathrm{KHNit}_{\mathrm{N}}$, and TNit are also the top three uncertainty sources among parameters. In EFDC model package, the kinetics of denitrification in the model are first order:

Denit $=\left(\frac{K H O R_{\mathrm{wo}}}{K H O R_{\mathrm{Do}}+D O}\right)\left(\frac{N O B}{K H D N_{\mathrm{v}}+N O 3}\right) A A N O X \cdot K_{\mathrm{Doc}}$

Where Denit $=$ denitrification rate $\left(\right.$ day $\left.^{-1}\right) ; N O 3$ $=\mathrm{NO}_{3}-\mathrm{N}$ concentration $\left(\mathrm{g} \mathrm{N} \mathrm{m}^{-3}\right) ; K_{D O C}=$ heterotrophic respiration rate of dissolved organic carbon at infinite dissolved oxygen concentration (1/day).

PTVs of parameters, $\mathrm{KHOR}_{\mathrm{DO}}$, KHDN ${ }_{\mathrm{N}}$ and AANOX, are small, So denitrification can be neglected in $\mathrm{NO}_{3}-\mathrm{N}$ modeling in the TGRR. 
Table 3: Uncertainty sources of $\mathrm{NH}_{4}-\mathrm{N}, \mathrm{NO}_{3}-\mathrm{N}, \mathrm{TN}$, and DO in the TGRR model

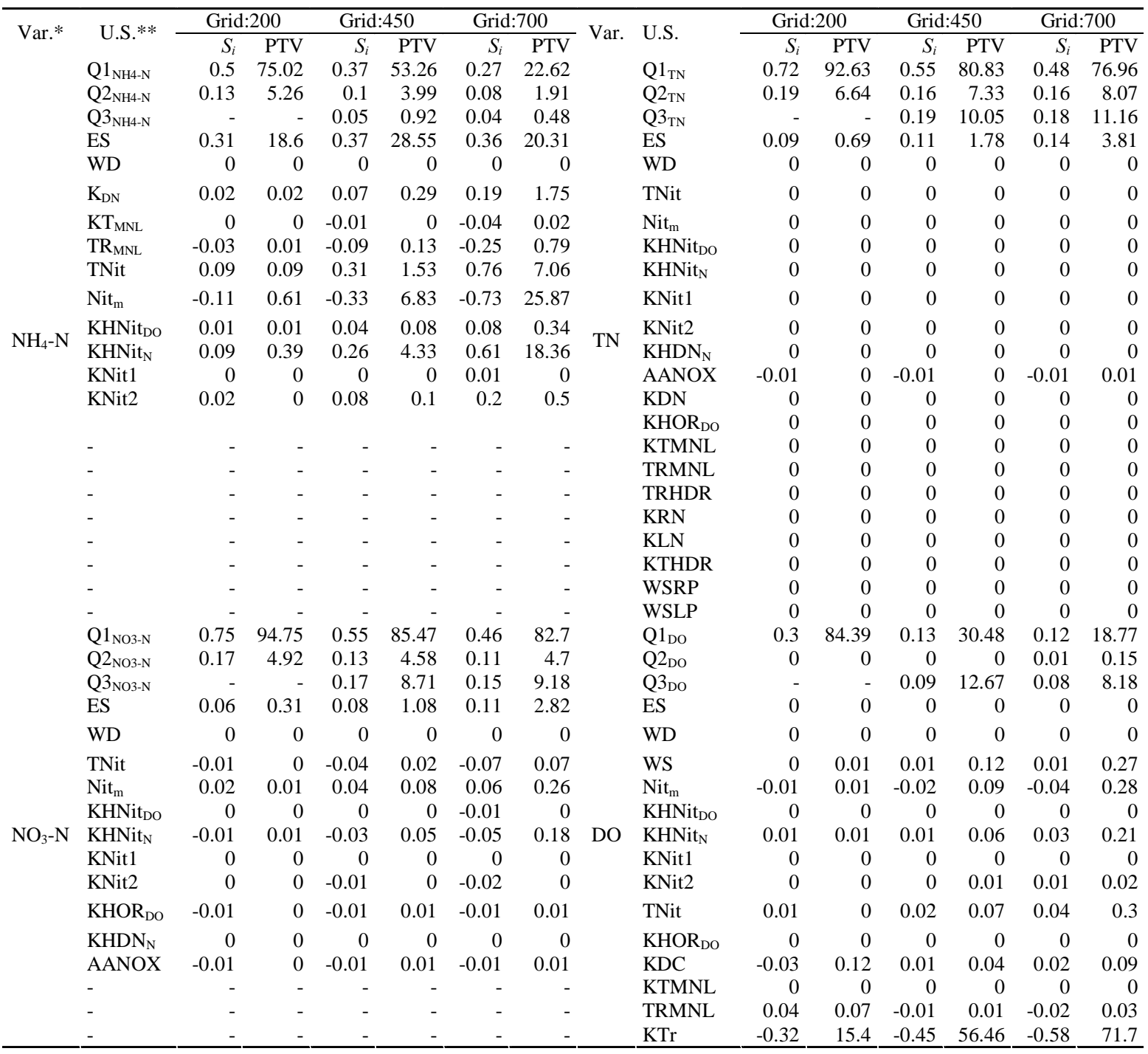

* variable;

** Uncertainty sources

As shown in Table 3, the uncertainty sources of TN are limited, and almost all uncertainty is from the inflow concentration from various sources. The parameter uncertainty was infinitely small, which was likely because the particulate organic nitrogen ratio was low in $\mathrm{TN}$, which can reduce settling to sediment, and transformation from $\mathrm{NH}_{4}-\mathrm{N}$ to $\mathrm{NO}_{3}-\mathrm{N}$ cannot change the TN concentration in the water column. In contrast to the nitrogen-related indices, DO always was a key index for uncertainty analysis (Brown and Barnwell, 1987; Melching and Yoon, 1996; Paliwal et al., 2007). In some models, such as QUAL2E (Brown and Barnwell, 1987) and WASP(Wool et al., 2001), BOD was used as an index to represent oxidation of organic carbon, and DO uncertainty analysis was related to some parameters of BOD. However, in the EFDC model package (Tetra Tech, 2007), organic carbon was used directly. Therefore, in this study, the uncertainty analysis of DO was analyzed using carbon and reaeration related parameters, and other inputs from various sources (Table 3).

As shown in Table 3, the inflow DO concentration 
from the Zhutuo station was dominant at grid 200 with a PTV of $84.39 \%$, but the effect decreased rapidly along the Changjiang River, with the PTV being $18.77 \%$ at grid 700 . The uncertainty from the Jialingjiang River was also small, and lower than that of the Wujiang River. In the downstream reaches, reaeration becomes the largest source of uncertainty for DO, and PTVs of KTr increased significantly from $15.40 \%$ at grid 200 to $71.70 \%$ at grid 700 . Water temperature is a primary factor leading to larger DO concentration uncertainty, which can be reflected by TNit indirectly. These findings are comparable to those of Brown and Barnwell (1987) and Abrishamchi et al. (2005) by QUAL2E. Nitrification and oxidation of organic carbon also contributed somewhat to DO uncertainty (e.g. PTV of $\mathrm{Nit}_{\mathrm{m}}$ is $0.28 \%$ at the grid 700 ).

\section{CONCLUSION}

In this study, the input and parameter uncertainty analysis was conducted using the FOEA method for some water quality variables in a water quality model. DO was a general variable in various uncertainty analyses, but $\mathrm{NH}_{4}^{-}$ $\mathrm{N}, \mathrm{NO}_{3}-\mathrm{N}$, and $\mathrm{TN}$ were scarce. Uncertainty analysis static water quality models were more common than dynamic ones. When compared to previously developed water quality models, the Three Gorges Model was superior in the following aspects: (1) it employed adequate and newer field data, which presents water quality conditions after impoundment; (2) it had long calibration and verification periods (lasting $1 \mathrm{y}$ ), which enabled it to better reflect the water quality of the TGR during low, average and high flow periods; (3) it considered more complex biochemical processes. The calibration and the verification results revealed that the model developed here can simulate the transport and fate of each variable satisfactorily with small errors. The results of the hydrodynamics were best and the RE values were less than $1 \%$. Based on the calibrated model, input and parameter uncertainty analysis were conducted systematically for $\mathrm{NH}_{4}-\mathrm{N}, \mathrm{NO}_{3}-\mathrm{N}, \mathrm{TN}$, and DO at three grid cells located in the upper, middle and downstream portions of the research area. Based on the results of this study, the following conclusions can be drawn: (a) for nitrogen related variables, inflow from upstream, two tributaries and external sources were the main sources of uncertainty; (2) for $\mathrm{NH}_{4}-\mathrm{N}$ and $\mathrm{NO}_{3}-\mathrm{N}$, nitrification related parameters also contributed to the uncertainty; (3) for DO, reaeration is a key source of uncertainty, especially at middle and downstream reaches.

\section{ACKNOWLEDGEMENTS}

Many thanks are given to Mr. Paul M. Craig at Dynamic Solution LLC. for providing the full version EFDC Explorer software and his guidance. This study was supported by the National Natural Science Foundation of China (NO. 40771193) and Program for Changjiang Scholars and Innovative Research Team in University (No.IRT0809).

\section{REFERENCES}

Abrishamchi, A.; Tajrishi, M.; Shafieian, P., (2005). Uncertainty analysis in QUAL2E model of Zayandeh-Rood River. Water Environ. Res., 77 (3), 279-286 (8 pages).

Bobba, A. G.; Singh, V. P.; Bengtsson, L., (1996). Application of First-Order and Monte Carlo analysis in watershed water quality models. Water Res. Manage., 10 (3), 219-240 (22 pages).

Brown, L. C.; Barnwell, T. O., (1987). The enhanced stream water quality models QUAL2E and QUAL2E-UNCAS: Documentation and user manual. US EPA, Athens, Georgia, USA.

Cerco, C. F.; Cole, T. M., (1994). Three-dimensional eutrophication model of Chesapeake Bay: Volume1, main report. US Army Engineer Waterways Experiment Station, Vicksburg, Mississippi, USA.

Chapra, S.; Pelletier, G.; Tao, H., (2007). QUAL2K: A modeling framework for simulating river and stream water quality, version 2.07: documentation and users manual. Civil and Environ. Eng. Dept., Tufts University, Medford, Massachusetts, USA.

Chen, H. W.; Yu, R. F.; Liaw, S. L.; Huang, W. C., (2010). Information policy and management framework for environmental protection organization with ecosystem conception. Int. J. Environ. Sci. Tech., 7 (2), 313-326 (14 pages).

Deng, C. G., (2007). The study of eutrophication in the three gorges reservoir region. Chinese Environment Press, Beijing.

Denham, C. R., (2006). SeaGrid orthogonal grid maker for matlab.

DHI, (2003). MIKE 11: A modelling system for rivers and channels:short introduction tutorial. DHI Software, Hørsholm, Denmark.

EPA, (2009). Total maximum daily loads for the Nimishillen Creek watershed. OhioEPA, Columbus, Ohio, USA.

Franceschini, S.; Tsai, C. W., (2010). Assessment of uncertainty sources in water quality modeling in the Niagara River. Adv. Water Res., 33 (4), 493-503 (11 pages).

Huang, Z. L.; Li, Y. L.; Chen, Y. C.; Li, J. X.; Xing, Z. G., (2006). Water quality prediction and water environmental carrying capacity calculation for Three Gorges Reservoir. China Waterpower Publisher, Beijing.

Igbinosa, E. O.; Okoh, A. I., (2009). Impact of discharge wastewater effluents on the physico-chemical qualities of a receiving watershed in a typical rural community. Int. J. Environ. Sci. Tech., 6 (2), 175-182 (8 ages).

Igwe, J. C.; Abia, A. A.; Ibeh, C. A., (2008). Adsorption kinetics and intraparticulate diffusivities of $\mathrm{Hg}$, $\mathrm{As}$ and $\mathrm{Pb}$ ions on unmodified and thiolated coconut fiber. Int. J. Environ. Sci. Tech., 5 (1), 83-92 (10 pages).

Ji, Z. G., (2008). Hydrodynamics and water quality: Modeling 
rivers, lakes and estuaries. Wiley-Interscience, Hoboken, New Jersey.

Karim, M. R.; Sekine, M.; Ukita, M., (2002). Simulation of eutrophication and associated occurrence of hypoxic and anoxic condition in a coastal bay in Japan. Mar. Pollut. Bull., 45 (1-12), 280-285 (6 pages).

Kuok, K. K.; Harun, S.; Shamsuddin, S. M., (2010). Particle swarm optimization feedforward neural network for modeling runoff. Int. J. Environ. Sci. Tech., 7 (1), 67-78 (12 pages).

Li, J. X.; Liao, W. G.; Huang, Z. L., (2002). Numerical simulation of water quality for the Three Gorges Project Reservoir. Shuili Xuebao(China), 12, 7-10 (4 pages).

Melching, C. S.; Yoon, C. G., (1996). Key sources of uncertainty in QUAL2E model of Passaic River. J. Water Res. Plan. Manage., 122 (2), 105-113 (9 pages).

MEP, (2010). Three Gorges Bulletin. Ministry of Environmental Protection, Beijing, China.

Nagheeby, M.; Kolahdoozan, M., (2010). Numerical modeling of two-phase fluid flow and oil slick transport in estuarine water. Int. J. Environ. Sci. Tech., 7 (4), 771-784 (14 pages).

Paliwal, R.; Sharma, P.; Kansal, A., (2007). Water quality modelling of the river Yamuna (India) using QUAL2EUNCAS. J. Environ. Manage., 83 (2), 131-144 (14 pages).

Radwan, M.; Willems, P.; Berlamont, J., (2004). Sensitivity and uncertainty analysis for river quality modeling. J. Hydroinform., 6 (2), 83-99 (17 pages).

Ratto, M.; Saltelli, A., (2001). GLUEWIN user manual, in model assessment in integrated procedures for environmental impact evaluation: Software prototypes. Joint Research Centre of European Commission, Institute for the Protection and Security of the Citizen., Ispra, Italy.

Shah, B. A.; Shah, A. V.; Singh, R. R., (2009). Sorption isotherms and kinetics of chromium uptake from wastewater using natural sorbent material. Int. J. Environ. Sci. Tech., 6 (1), 83-92 (14 pages).

Soner Kara, S.; Onut, S., (2010). A stochastic optimization approach for paper recycling reverse logistics network design under uncertainty. Int. J. Environ. Sci. Tech., 7 (4), 67-78 (14 pages).

Tetra Tech, I., (2007). Theenvironmental fluid dynamics code user manual US EPA Version 1.01. Tetra Tech, Inc., Fairfax,Virginia,USA.

Tomassini, L.; Reichert, P., (2007). Robust Bayesian uncertainty analysis of climate system properties using Markov Chain Monte Carlo methods. J. Climate, 20 (7), 1239-1254 (16 pages).

Turner, D., F. ;Pelletier, G. J.; Kasper, B., (2009). Dissolved Oxygen and $\mathrm{pH}$ Modeling of a Periphyton Dominated, Nutrient Enriched River. J. Environ. Eng., 135 (8), 645652 (8 pages).

USEPA, (1999). Protocol for developing nutrient TMDLs first edition. USEPA, Washington,D.C. USA.

Wool, T.A.; Ambrose, R. B.;Martin, J. L.; Comer, E. A., (2001). Water quality analysis simulation program (WASP) version 6.0 draft: user' $\mathrm{s}$ manual. US Environmental Protection Agency-Region 4, Atlanta, USA.

Yu, X. Z., (2008). Simulation study on the effect of sediment on phosphorus on the Three Gorges Reservoir. Ph.D.dissertation, Shool of Environment, Beijing Normal University.

Zhang, H. X.; Yu, S. L., (2004). Applying the First-Order Error analysis in determining the margin of safety for total maximum daily load computations. J. Environ. Eng. ASCE, 130 (6), 664-673 (10 pages).

Zhang, J. X.; Liu, Z. J.; Sun, X. X., (2009). Changing landscape in the Three Gorges Reservoir Area of Yangtze River from 1977 to 2005: Land use/land cover, vegetation cover changes estimated using multi-source satellite data. Int. J. Appl. Earth Obs., 11 (6), 403-412 (10 pages).

Zhen, B. H.; Wang, L. J.; B., G., (2009). Load of non-point source pollutants from upstream rivers into Three Gorges Reservoir. Res. Environ., 22 (2), 125-131 (7 pages).

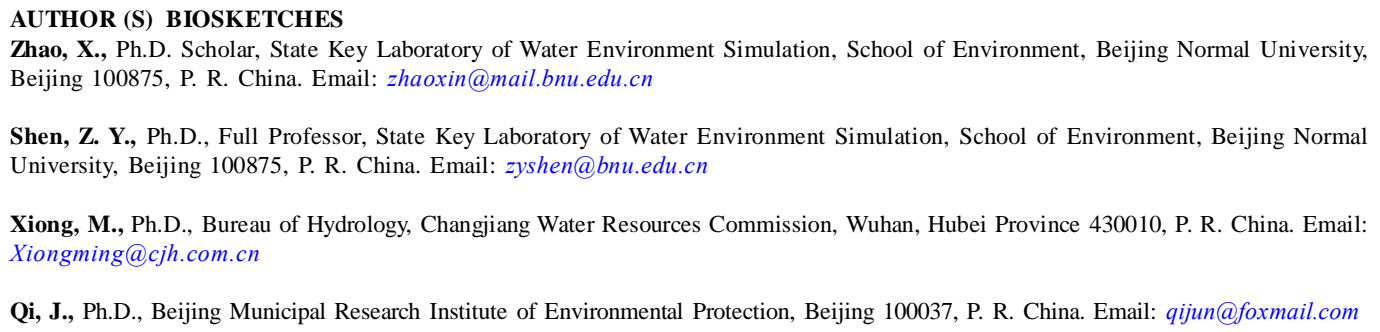

How to cite this article: (Harvard style)

Zhao, X.; Shen, Z. Y.; Xiong, M.; Qi, J., (2011). Key uncertainty sources analysis of water quality model using the first order error method. Int. J. Environ. Sci. Tech., 8 (1), 137-148. 